\title{
A ESSENCIALIDADE DO PLANEJAMENTO ECONÔMICO PARA O ALCANCE DO DESENVOLVIMENTO NACIONAL
}

\author{
THE ESSENTIALITY OF ECONOMIC PLANNING TO THE \\ ACHIEVEMENT OF NATIONAL DEVELOPMENT
}

\begin{abstract}
Suzy Elizabeth Cavalcante Koury
Doutora pela Universidade Federal de Minas Gerais (UFMG). Professora do PPGD Stricto Sensu em Direito, Políticas Públicas e Desenvolvimento e do Curso de graduação em Direito do Centro Universitário do Estado do Pará (CESUPA). Desembargadora do Tribunal Regional do Trabalho da $8^{\mathrm{a}}$ Região. Líder do grupo de pesquisa Emprego, subemprego e políticas públicas na Amazônia e vice-líder do grupo Mineração e Desenvolvimento Regional na Amazônia (MinAmazônia).
\end{abstract}

Amanda Naif Daibes Lima

Pós-graduanda em Direito Público. Membro do grupo de pesquisa (CNPQ) Mineração e Desenvolvimento Regional na Amazônia (MinAmazônia). Advogada.

Resumo: Este artigo estuda o instituto do planejamento econômico com base nos ensinamentos do professor Washington Peluso Albino de Souza e à luz da Constituição Federal de 1988. Apesar de ser uma técnica que possibilita a intervenção do Estado no domínio econômico, observa-se o seu gradual abandono, o que é prejudicial ao desenvolvimento nacional, um dos objetivos fundamentais da República. Diante desse contexto, questiona-se: como o planejamento econômico pode contribuir para a efetivação do desenvolvimento nacional? Para responder à problemática proposta, são objetivos deste ensaio a análise conceitual do instituto, o estudo das políticas de planejamento nacionalistas (1930 a 1960), do período de crise democrática (1961 a 1964) e do regime autoritário (1964 a 1985). Conclui-se pela necessidade de condução do planejamento em bases democráticas, enquanto dever do Estado, a fim de que seja viabilizado o alcance do desenvolvimento nacional.

Palavras-chave: Constituição Federal de 1988; Desenvolvimento Nacional; Estado Interventor; Planejamento Econômico.

Abstract: This article studies the institute of economic planning based on the teachings of Professor Washington Peluso Albino de Souza and in the light of the Federal Constitution of 1988. Despite being a technique that allows the State to intervene in the economic domain, its gradual abandonment is observed, with harmful effects to national development, one of the fundamental objectives of the Brazilian Republic. Given this context, the question arises: how can economic planning contribute to the accomplishment of national development? To answer the proposed problem, this essay will discuss the conceptual analysis of the institute and the study of the nationalist planning policies (1930 to 1960), in the period of democratic crisis (1961 to 1964) and in the authoritarian regime (1964 to 1985). It concludes that there is a need 
to conduct planning on a democratic basis, as a duty of the State, in order to make national development feasible.

Keywords: Federal Constitution of 1988; National Development; Intervening State; Economic Planning.

Sumário: Introdução. 1 A Constituição Econômica de 1988 e o Instituto do Planejamento de Acordo com os Ensinamentos de Washington Peluso Albino de Souza. 2 A Adoção do Planejamento no Brasil. 3 O Planejamento Possível na Democracia Brasileira. Considerações Finais. Referências.

\section{INTRODUÇÃO}

O planejamento econômico é uma técnica de intervenção do Estado no domínio econômico. Como instituto de Direito Econômico que é, relacionase à ideologia constitucionalmente adotada para buscar a realização dos objetivos dispostos na Constituição brasileira de 1988, dentre os quais se destaca o desenvolvimento nacional.

Este ensaio visa demonstrar que o Estado brasileiro abandonou, há algum tempo, uma tendência demonstrada na evolução do seu sistema político-econômico: a política econômica planificada, o que importa no descumprimento do mandamento constitucional de efetivar o planejamento. Consequentemente, observa-se grande prejuízo na busca pelo desenvolvimento nacional, um dos objetivos fundamentais da República.

Diante disso, investigar-se-á: como o planejamento econômico pode contribuir para a efetivação do desenvolvimento nacional?

Com o intuito de responder à problemática proposta, este artigo está dividido em cinco seções, sendo a primeira esta introdução. Na segunda seção, estuda-se o planejamento enquanto instituto de Direito Econômico e dever do Estado, à luz da Constituição Federal de 1988 e segundo os ensinamentos do professor Washington Peluso Albino de Souza.

A terceira seção traz um histórico das principais políticas de planejamento realizadas no Brasil, por meio da análise das políticas nacionalistas de Getúlio Vargas e de Juscelino Kubitschek (1930 a 1960), seguidas das políticas adotadas no período de crise democrática (1961 a 1964) para se chegar a um planejamento autoritário (1964 a 1985), quando 
se constata a busca pelo crescimento sem desenvolvimento econômico e o gradativo abandono do dever de planejar.

O breve recorte histórico faz-se necessário para demonstrar de que maneira a política econômica do planejamento foi construída até se chegar ao modelo que se tem hoje, descrito pela Constituição de 1988.

A quarta seção enfrenta a necessidade de retorno do planejamento em bases democráticas, defendendo-se uma atuação positiva do Estado na busca do desenvolvimento nacional, aos moldes do que faz a China.

\section{A CONSTITUIÇÃO ECONÔMICA DE 1988 E O INSTITUTO DO PLANEJAMENTO DE ACORDO COM OS ENSINAMENTOS DE WASHINGTON PELUSO ALBINO DE SOUZA}

A $1^{a}$ Guerra Mundial (1914-1918) foi o cenário propício para o nascimento da disciplina de Direito Econômico, que é associada ao surgimento das Constituições Econômicas, consoante as quais a economia foi regulamentada para submeter a atuação dos agentes privados à guerra, de maneira que a sociedade foi conduzida para o que se nomeou de "economia de guerra" (COMPARATO, 1989, p. 455).

Com o fim da Guerra, os problemas econômicos e sociais permaneceram e acentuaram-se, de modo que a atuação estatal na economia, em conjunto com medidas de proteção social, tornou-se uma preocupação das nações, intensificada com a crise da Bolsa de Nova Iorque de $1929^{1}$. A partir de então, o papel do Estado como regulador e propulsor econômico estimulou debates acerca da fragilidade do liberalismo econômico outrora praticado.

Entretanto, foi somente no século XX que vieram à tona discussões sobre os problemas voltados à realidade social, os quais não encontravam respostas nos ramos tradicionais do direito do século XIX, a exemplo das discussões sobre o desenvolvimento e o planejamento econômico. Tratam-

\footnotetext{
${ }^{1}$ Também conhecida como Grande Depressão, teve início nos Estados Unidos em 1929 e se estendeu pela década de 1930, por todo o mundo capitalista, com desemprego generalizado e queda do consumo.
} 
se das Constituições Econômicas que rechaçam o modelo de mercado autorregulado, opondo-se à realidade e propondo-se a alterá-la mediante a positivação de tarefas e objetivos de política econômica direcionada à concretização da ideologia constitucionalmente adotada ${ }^{2}$.

De acordo com o professor Washington Peluso Albino de Souza (2002, b, p. 23), o aspecto distintivo das Constituições Econômicas é a existência do "econômico" no texto constitucional, presente "[...] na tessitura estrutural desta [Constituição Geral], não importa se na condição de Parte, Título, Capítulo ou em artigos esparsos", de modo que se pode dizer que a Constituição Econômica compreende a parte integrante de um todo constitucional.

Em vista disso, a Constituição Econômica não é apenas um recorte presente no título VII da Ordem Econômica, mas é integrada por dispositivos esparsos que abordam o "econômico", a exemplo dos valores sociais do trabalho e da livre iniciativa como princípios republicanos, da propriedade privada enquanto direito fundamental, de sua função social e da possibilidade de desapropriação, dentre outros dispositivos, pois deve ser compreendida como uma unidade, mesmo abrangendo vários campos e áreas específicas, o que inclui a economia (BERCOVICI, 2005, p. 13).

Ao conjugar elementos sociais e liberais, a Constituição Econômica, ao contrário das Constituições liberais que se utilizavam de uma política de manutenção da conjuntura, propõe-se a efetivar a transformação das estruturas sociais (COMPARATO, 1965, p. 463-465).

A transformação das estruturas sociais e o consequente rompimento do equilíbrio é efetivada pela adoção de uma política econômica desenvolvimentista, a qual se opõe à estagnação, ao mero crescimento e ao subdesenvolvimento típico do liberalismo econômico. Nesse sentido, a ideologia intervencionista é necessária, em maior ou menor intensidade, na busca do desenvolvimento (SOUZA, 1994, p. 330-331).

\footnotetext{
${ }^{2}$ Washington Albino define a ideologia constitucionalmente adotada como o estabelecimento das bases jurídicas da prática econômica a ser seguida de acordo com o texto constitucional. Desta forma, não se trata da adoção de um modelo puro de ideologia - liberalismo, socialismo ou protecionismo -, mas sim a manifestação do tratamento do tema econômico pela Constituição (SOUZA, 2002, b).
} 
$\mathrm{O}$ agente promotor do desenvolvimento é o Estado, o detentor do poder econômico público. Ao fazer uso do seu poder mediante os institutos de direito econômico, a exemplo do planejamento, o Estado pode agir diretamente na economia por meio das empresas públicas e sociedades de economia mista, como ocorre no ordenamento jurídico brasileiro (art. 173, $\mathrm{CF} / 88$ ), assim como pode criar condições para que a iniciativa privada, no exercício do poder econômico privado, participe do projeto desenvolvimentista.

A Ordem Econômica prevista na Constituição de 1988 possibilitou a intervenção estatal sobre e no domínio econômico (GRAU, 2012, pp. 143), com o objetivo de resguardar os princípios, os direitos e os objetivos constitucionais, com ênfase à defesa do meio ambiente, à redução das desigualdades regionais e ao desenvolvimento nacional. Por assim ser, o Estado é chamado a atuar no domínio econômico para que sejam alcançados os objetivos constitucionais contidos na ideologia constitucionalmente adotada, a exemplo dos dispostos no art. $3^{\circ}$ da CRFB $/ 88^{3}$.

Nesse sentido, a intervenção indireta ou sobre o domínio econômico reflete a atuação do Estado enquanto agente normativo e regulador, orientando como a atividade econômica será exercida pelo particular e pelo próprio poder público, de maneira que poderá fazê-lo por normas de direção ou por normas de indução. Sobre esta distinção, aduz Grau (2012, p.143144):

[...] quando o faz por direção, o Estado exerce pressão sobre a economia, estabelecendo mecanismos e normas de comportamento compulsório para sujeitos da atividade econômica em sentido estrito. Quando o faz, por indução, o Estado manipula os instrumentos de intervenção em consonância e na conformidade das leis que regem o funcionamento dos mercados [...]

\footnotetext{
${ }^{3}$ Art. $3^{\circ}$. Constituem objetivos fundamentais da República Federativa do Brasil: I - construir uma sociedade livre, justa e solidária; II - garantir o desenvolvimento nacional; III - erradicar a pobreza e a marginalização e reduzir as desigualdades sociais e regionais; IV - promover o bem de todos, sem preconceitos de origem, raça, sexo, cor, idade e quaisquer outras formas de discriminação (BRASIL, 1988).
} 
Além disso, observa-se que a intervenção estatal na economia, como toda medida de política econômica, somente é justificada para atender aos objetivos traçados pela ideologia constitucionalmente adotada, uma vez que o campo econômico é área de atuação típica da iniciativa privada, ao passo que os serviços públicos são áreas de atuação do Estado. Dessa forma, a intervenção deve estar associada aos fins constitucionais, a exemplo da busca pelo desenvolvimento.

Ao fazer referência ao desenvolvimento nacional no âmbito do planejamento econômico, Adri (2010, p. 114) defende tratar-se da constante melhoria dos meios essenciais à sobrevivência dos indivíduos e do Estado, com o intuito de alcançar o bem-estar de todos.

Especialmente nos países subdesenvolvidos ou em desenvolvimento, como é o caso do Brasil, o instituto do planejamento é indispensável ao estabelecimento de uma política econômica pelo Estado, uma vez que "[...] os pressupostos da economia subdesenvolvida não coincidem com os referenciais definidores do ideal liberal dos quais as desenvolvidas mais facilmente se aproximam" (SOUZA, 1994, p. 337), muito embora os países desenvolvidos jamais tenham vivenciado, na prática, a teoria liberal clássica sob o slogan de Estado mínimo não - ou pouco - interventor.

O período entre guerras (1919-1938), além de favorecer o desenvolvimento da disciplina Direito Econômico, trouxe à tona a crise do capitalismo liberal, aspecto que propiciou a adoção do planejamento por países que, outrora, repudiavam-no, como é o caso dos Estados Unidos, que adotaram planos parciais ou setoriais (SOUZA, 1994, p. 296).

No mesmo sentido, Ianni (2009, p. 51) entende que a técnica do planejamento como política econômica do Estado começou a ser introduzida no Brasil durante a II Guerra Mundial ou, ao menos, foi a partir desse período que começou a fazer parte do pensamento dos governantes como meio racional de tomada de decisões no âmbito econômico-financeiro.

A justificativa para a aceitação do planejamento decorreu dos próprios dilemas e das problemáticas trazidas pelas Guerras, uma vez que o setor privado não estava preparado para fazer face às novas exigências de capital, tecnologia e organização, de tal sorte que as perspectivas de desenvolvimento econômico demandavam a formulação e a utilização de novas técnicas de ação, papel do instituto em comento (IANNI, 2009, p. 61). 
Desta forma, diversos países passaram a adotar o planejamento em consonância com o respectivo regime político, de modo a associar o plano à ideologia disposta na Constituição. Assim, é possível afirmar que o instituto do planejamento independe de regimes ou de ideologias políticas, uma vez que se trata da mais completa técnica de intervenção do Estado no domínio econômico com o intuito de alcançar um objetivo pré-determinado, de maneira que obedeça ao regime político ao qual se aplica (SOUZA, 1994, p. 289- 294).

Destarte, a associação do ato de planejar aos modelos ditatoriais de "direita" ou de "esquerda" não encontra razão para subsistir na ordem constitucional brasileira, que conjuga princípios de ordem liberal e de ordem social por intermédio do princípio da economicidade ${ }^{4}$, o qual é absorvido pela lei do plano ao conciliar a ideologia constitucionalmente adotada com as medidas de política econômica.

Ao contrário, vislumbra-se que o instituto do planejamento econômico, por ser uma técnica de intervenção do Estado no domínio econômico, deve ser compatibilizado com o regime democrático de governo (ADRI, 2010, p. 126), aspecto que encontra guarida na Constituição de 1988, a qual protege princípios de ideologias opostas que acabam por gerar uma limitação uns aos outros, a exemplo do direito à propriedade e a necessidade de que seja observada sua função social.

Em relação a essa dualidade principiológica, entende-se que a política do planejamento é a forma conciliatória, por excelência, de pontos aparentemente contraditórios, de maneira que "os países que procuram conciliar esses pontos aparente ou teoricamente contraditórios têm encontrado o caminho do Planejamento como capaz de corrigir até mesmo

\footnotetext{
${ }^{4}$ Washington Albino define o princípio da economicidade em seu duplo viés: quanto ao entendimento e quanto à função. Quanto ao entendimento, é a busca do equilíbrio, o sacrifícioprazer, que permite a valoração na linha de maior vantagem, de modo que, em determinadas circunstâncias, o princípio a ser aplicado será aquele que melhor conduza à ideologia constitucionalmente adotada. Quanto à função, é o instrumento hermenêutico de harmonização de dispositivos constitucionais aparentemente contrários, porque baseados em ideologias distintas, como a proteção à propriedade privada (tipicamente capitalista) e a sua função social (tipicamente socialista). (SOUZA, 1994).
} 
o intervencionismo de Estado em bases autoritárias" (SOUZA, 2002, b p. 228).

Em termos práticos, o planejamento reflete a utilização do plano com o intuito de racionalizar o uso de recursos escassos a fim de obter melhores resultados do seu aproveitamento, o que foi feito por muitas nações subdesenvolvidas (SOUZA 2002, b p. 171).

A respeito do plano, Souza (2002a p. 174) aponta que o aspecto jurídico dessa peça técnica permite que se a tenha como "um diploma definidor de direitos e obrigações, ricamente comprometido com objetivos políticos, mas especialmente caracterizado como instrumento normativo de relações entre Estado e os cidadãos".

De acordo com Souza (1980, p. 453), o uso do planejamento, concretizado por meio da peça técnica que é o plano, é uma opção política, uma vez que se parte de uma decisão de planejar e de conduzir os fatos da vida econômica da sociedade.

Em outras palavras, o plano, uma vez transformado em lei, é utilizado como instrumento de política econômica, cujo objetivo é a realização dos princípios da ideologia constitucionalmente definida. Ao invés de deter-se na vida econômica do país, o plano traduz a onipresença do Estado ao abranger os aspectos da vida social, econômica e cultural (SOUZA, 2002b, pp. 197-198).

É possível vislumbrar a previsão do instituto do planejamento econômico no artigo 174 da CRFB/ $/ 88^{5}$, que define o Estado como agente normativo e regulador da atividade econômica, além de possuir as funções de fiscalização, incentivo e planejamento. Ao comentar este dispositivo constitucional, Adri (2010, p. 162) entende ser o instituto do planejamento

\footnotetext{
${ }^{5}$ Art. 174. Como agente normativo e regulador da atividade econômica, o Estado exercerá, na forma da lei, as funções de fiscalização, incentivo e planejamento, sendo este determinante para o setor público e indicativo para o setor privado. $\S 1^{\circ}$ A lei estabelecerá as diretrizes e bases do planejamento do desenvolvimento nacional equilibrado, o qual incorporará e compatibilizará os planos nacionais e regionais de desenvolvimento. [...] (BRASIL, 1988).
} 
uma mola propulsora do desenvolvimento equilibrado, pois associa os poderes político e econômico em prol da busca de sua concretização.

Nesse sentido, o planejamento evidencia a importância da iniciativa privada na vida econômica, de maneira que ela é incorporada ao plano mediante as medidas de incentivo previstas constitucionalmente. Para além disso, Souza (1994, p. 298) aponta que

[...] aprovado o Plano de Governo as empresas, voluntária ou involuntariamente, incluem-se nos seus "objetivos". Podem fazê-lo pela adesão direta, quer assumindo a realização de "objetivos" ali traçados, quer se beneficiando de "estímulos" de diversas espécies nele oferecidos. Mas, também ao se ajustar, inevitavelmente à Política Econômica, ao "modelo" implantado pelo Plano, toda a iniciativa privada com ele estará comprometida [...]

Desse modo, é possível afirmar que o planejamento é capaz de unir as dimensões privada e pública em prol da concretização da ideologia constitucionalmente adotada, uma vez que há a convergência de interesses de intervenção do Estado com a liberdade individual, a fim de que se alcance um objetivo definido constitucionalmente.

Todavia, o planejamento econômico, assim como toda política econômica, não é concretizado pela simples existência do Estado, de modo que se faz necessário um corpo técnico regulador e fiscalizador, com metas bem delineadas para que o objetivo final seja alcançado. Ao observarmos a história brasileira de adoção deste instituto, nota-se que, gradualmente, o Estado diminuiu o regime jurídico planejador, conforme será abordado no tópico a seguir.

\section{A ADOÇÃO DO PLANEJAMENTO NO BRASIL}

Bercovici (2003, p. 308) discorre sobre alguns momentos de adoção do planejamento na história brasileira, dentre os quais serão destacados o Plano de Metas, no período compreendido entre 1956 a 1961, e o II Plano Nacional de Desenvolvimento, entre os anos 1975 e 1979. 
Considerando que as políticas econômicas não podem ser dissociadas da ordem constitucional que as embasa, é importante que os planos a seguir sejam tratados em conjunto com a Constituição vigente à época.

O Plano de Metas, implementado no governo de Juscelino Kubitschek, foi a primeira experiência de planejamento do Brasil, cujo programa objetivava a melhoria da infraestrutura brasileira, ao conferir unidade aos projetos e aos programas nele previstos (BERCOVICI, 2015, p. 400).

A execução do Plano ficou a cargo de órgãos especiais, com ênfase ao Banco Nacional de Desenvolvimento (BNDE), responsável por coordenar os programas governamentais, além de destinar os recursos públicos a setores estratégicos (ADRI, 2010, p. 123).

O BNDE, além de possibilitar a realização de empréstimos destinados a investimentos em setores estratégicos da economia brasileira, foi responsável por aprimorar as decisões e a execução de diversos programas setoriais do Plano.

Segundo Bercovici (2015, pp. 399-403), Juscelino Kubitschek (JK) foi responsável por associar os ideais de desenvolvimento, planejamento e democracia, de modo a pensar em um projeto nacional para o Brasil, mas foi sob o governo de Vargas que tudo começou.

De acordo com Ianni (2009, p. 28), o governo Vargas, no período de 1930 a 1945, adotou diversas medidas econômicas, além de ter realizado inovações institucionais que apontaram para uma nova fase nas relações entre o Estado e as políticas econômicas engendradas.

Essas medidas alcançaram a maior parte das esferas da sociedade nacional, de maneira a formalizar, em novos níveis, as condições de funcionamento das forças produtivas no mercado brasileiro. Com isso, Ianni (2009, p. 35-36) aponta que houve uma "reformulação dos ideais e padrões de tipo capitalista", uma vez que o liberalismo brasileiro era voltado às relações externas do país e o Governo, ao estimular a valorização do mercado interno e o funcionamento de suas forças produtivas, promoveu a reformulação de padrões e valores do capital. Nesse sentido, prossegue o autor:

[...] nos anos de 1930-1945, o Governo Federal criou comissões, conselhos, departamentos, institutos, companhias, fundações e 
formulou planos. Além disso, promulgou leis e decretos. E incentivou a realização de debates, em nível oficial e oficioso, sobre os problemas econômicos, financeiros, administrativos, educacionais, tecnológicos e outros [...]. Tratava-se de estudar, coordenar, proteger, disciplinar, reorientar e incentivar as atividades produtivas em geral. Ou seja, tratava-se de formalizar, em novos níveis, as condições de intercâmbio e funcionamento das forças produtivas no mercado brasileiro. [...] (IANNI, 2009, p. 35).

Ademais, foi ainda no governo Vargas que a Constituição de 1937 dispôs sobre diretrizes de cunho nacionalista e intervencionista, prevendo, explicitamente, a possibilidade de atuação do poder público em qualquer esfera da economia.

Um exemplo da conjugação das políticas de planejamento adotadas, primeiramente, por Vargas e continuadas por Kubitschek, é a passagem da fase inicial de industrialização, a qual ocorreu a partir de 1930, para a fase de industrialização pesada mediante a articulação dos capitais estatal, privado nacional e estrangeiro, culminando com a implementação do Plano de Metas, após o qual é possível verificar, por exemplo, a integração horizontal da indústria automobilística.

Somado a isso, a partir do governo J.K. é possível vislumbrar o desenvolvimento do setor ferroviário, o que decorreu dos investimentos realizados em transportes e em ampliações de rodovias. Além da mudança de perspectiva nos setores ferroviário, elétrico e de integração econômica, Kubitschek criou várias universidades federais no Brasil, dentre as quais a Universidade Federal do Pará (1957). Em razão disso, Bercovici (2015, p. 416) atesta que:

[...] seja na área da organização jurídica, como na organização administrativa do processo de desenvolvimento e do planejamento, o governo do Presidente Juscelino Kubitschek foi absolutamente dinâmico, inovador, dando continuidade ao projeto que hoje chamamos de nacional-desenvolvimentista.

Nesse contexto, a Constituição de 1946 favoreceu o instituto do planejamento ao caracterizar-se como neoliberal e democrática, com o 
objetivo de adaptar a situação brasileira à nova realidade do pós-guerra (SOUZA, 2002b, p. 13).

A Constituição de 1946, além de possuir capítulo próprio a respeito da ordem econômica e social, permitiu a desapropriação e a intervenção do Estado, de tal sorte que houve referência expressa aos planos regional e setorial.

Para Souza (2002b, p. 184-185), a base constitucional existente nesse período oportunizou o surgimento de um sistema de planejamento no Brasil e, em paralelo, serviu de justificativa à elaboração de leis aos respectivos planos, a exemplo da Lei n ${ }^{\circ} 1.102$ de 1950, que aprovou o Plano SALTE ${ }^{6}$.

O II Plano Nacional de Desenvolvimento (PNDE) foi implementado no período de ditadura militar (1975-1979), cujo objetivo consistia no crescimento econômico acelerado, visando concentrar os atos no Poder Executivo e afastar a participação efetiva do Poder Legislativo.

No período em questão, o regime jurídico do planejamento foi implementado por meio do Ato Complementar $\mathrm{n}^{\circ} 43$ de 1969, modificado pelo Ato Complementar no 76 de 1969 e pelo Decreto $n^{\circ} 71.353$ de 1972 (ADRI, 2010, p. 123).

Segundo Adri (2010, p. 124), no período posterior ao II PNDE, inexistiu um regime jurídico de planejamento, de maneira que o desenvolvimento econômico passou a depender da gestão isolada de medidas de estabilização econômica a ponto de o Estado assumir uma posição de insuficiência de implementação das políticas públicas harmoniosas e de caráter global.

Quando se adentra no regime autoritário, o qual corresponde aos governos dos anos de 1964 a 1984, é possível observar políticas voltadas à redução da taxa de inflação, ao incentivo de exportação de produtos agrícolas, ao estímulo à entrada de capital e tecnologia estrangeira e à contenção dos níveis salariais, dentre outras. Como bem sintetiza Ianni (2009, p. 215), "nesses anos (1964-1970), o poder público foi levado a interferir praticamente em todos os setores do sistema econômico nacional".

\footnotetext{
${ }^{6}$ O Plano SALTE foi lançado no governo de Eurico Gaspar Dutra (1946-1950) e objetivava o desenvolvimento dos setores de saúde, alimentação, transporte e energia (acrônimo SALTE).
} 
Ao analisar o período de ditadura militar pelo qual o Brasil passou (1964-1985), Tavares (2015, pp.1047-1049) aponta que, em razão do neoliberalismo, houve alterações no poder político do Estado, aproximandoo de tal forma do poder econômico privado que houve uma promiscuidade entre o político e o econômico. Por assim ser, os interesses particulares acabaram por orientar as atividades do Estado predispostas à economia, de maneira que houve a redução da soberania estatal.

Em termos de política econômica, observou-se um modelo voltado para alguns setores econômicos, com consequências negativas no âmbito social mediante a exclusão da maior parte da população, de maneira que o desenvolvimento nacional ficou prejudicado ao serem priorizadas medidas de crescimento econômico, caracterizadas pela interferência do interesse privado nas decisões tomadas pelo Estado, aspecto que é favorecido pelo regime ditatorial, uma vez que a fiscalização e o controle de poder são poucos ou inexistentes (TAVARES, 2015, p. 1050 -1053).

Como nos primeiros anos de governo (1964-1967), a preocupação da política engendrada era com a redução da inflação. Tavares (2015, pp. 10571058) aponta que as pequenas e médias empresas foram sacrificadas em detrimento de uma suposta economia racional. Em decorrência disso, a alteração no sistema cambial extinguiu as subvenções de produtos básicos para o trabalhador, como o trigo e o petróleo, encarecendo os preços do pão e dos transportes, por exemplo. Somado a isso, houve a dissolução de sindicatos, a anulação do direito à greve e a proibição de reajuste salarial em períodos inferiores a um ano.

Contrariamente ao que havia sido feito por Vargas na busca do capital internacional para investimento no mercado interno, o Estado Ditatorial apoiou-se nos investimentos de multinacionais e no crédito internacional para incentivar as exportações e incrementar o mercado agroexportador, o que repercutiu na valorização dos setores de matéria-prima e de agricultura em detrimento do mercado interno.

Ao analisar o encaminhamento da economia brasileira a partir de 1960, Prado Júnior (2012, p. 327) já apontava para o retorno da relação do imperialismo com o velho sistema colonial brasileiro, fundada na exportação de produtos primários. Apesar das custosas tentativas de industrialização do país desde 1930, o sistema colonial brasileiro continua o mesmo do passado, ou seja, um sistema baseado na produção de matérias-primas e alimentos demandados no mercado internacional. 
Desta forma, o período marcado pelo "milagre econômico brasileiro"7 foi, na realidade, pautado em uma estrutura econômica voltada ao crescimento e ao mercado internacional, de modo a beneficiar uma pequena parcela da população brasileira e a concentrar a riqueza em partes do território, pois não foram distribuídas igualitariamente as benesses do aumento do Produto Nacional Bruto, o que se verifica pelo encarecimento de produtos essenciais, como o pão, e, em paralelo, pela facilidade na aquisição de bens de luxo e automóveis. Tratava-se de um crescimento econômico sem desenvolvimento (TAVARES, 2015, p. 1059-1062).

Dentre os planos governamentais que marcaram o período em apreço, além do II PND já mencionado, é possível destacar a reformulação das instituições, normas e técnicas voltadas ao mercado de capital e à força de trabalho mediante os seguintes instrumentos: Programa de Ação Econômica do Governo- PAEG (1964-1966), Plano Decenal de Desenvolvimento Econômico e Social (1967-1976), Programa Estratégico de Desenvolvimento (1968-1970), Metas e Bases para a Ação Governamental (1970-1972) e o I e III PND (1972- 1985) (IANNI, 2009).

Em linhas gerais, o PAEG visava à aceleração do ritmo de desenvolvimento econômico do país e à contenção do processo inflacionário, além de atenuar as tensões advindas dos desequilíbrios sociais e corrigir os déficits da balança de pagamentos, dentre outras medidas.

A partir desta política, houve a reformulação das relações de produção de acordo com as exigências da reprodução capitalista e da expansão do setor privado, de maneira que o Estado foi levado a interferir de modo profundo e sistemático nas relações econômicas para que as empresas privadas pudessem funcionar (IANNI, 2009, p. 220-222).

Ao comentar sobre a política econômica praticada pelos militares, Ianni (2009, p. 216) observa que houve uma hegemonia do Poder Executivo sobre os demais poderes durante os vinte e um anos de ditadura.

Diante do breve relato sobre a política de planejamento adotada pelos governos Vargas, J.K. pode-se afirmar que, durante a ditadura militar, houve um gradativo enfraquecimento deste instituto até o ponto de se abandonar a

\footnotetext{
${ }^{7}$ Período que vai de 1968 a 1973 em que houve elevado crescimento econômico do Brasil, com aumento do Produto Interno Bruto (PIB), da industrialização e com inflação baixa.
} 
busca do desenvolvimento nacional para que fosse realizada uma política excludente de crescimento econômico.

Ao voltarmos os olhos para a Constituição de 1988 e o Estado democrático de Direito instituído a partir de então, é possível afirmar que o Direito Econômico fornece as bases e os instrumentos para a concretização de uma política econômica democrática, a fim de que a ideologia constitucionalmente adotada seja efetivada. Um desses instrumentos é o planejamento, instituto que precisa ser revisitado para que se possa caminhar na direção do desenvolvimento nacional.

\section{O PLANEJAMENTO POSSÍVEL NA DEMOCRACIA BRASILEIRA}

A democracia moderna, enquanto forma de governo, nasceu com as revoluções liberais do século XVIII e, por muito tempo, guardou os ditames do liberalismo ao longo de suas reformulações. Atualmente, pauta-se na premissa de controle do poder pelo indivíduo, ou melhor, pelo povo, que é detentor do poder político outrora exercido pela Coroa (OLIVEIRA, 2015, p. 373-374).

Com a democracia houve a valorização da liberdade individual, de modo que não se aceitava a intervenção do Estado nas relações privadas. Ao contrário, as intervenções do Estado liberal limitavam-se à conjuntura de manutenção do equilíbrio natural do mercado (COMPARATO, 1965 p. 464).

Quando transmutada para a ordem econômica, a liberdade irrestrita pressupunha que a sociedade estivesse submetida às exigências da autorregulação, o que se construiu paulatinamente mediante a defesa da separação entre a economia e a política (Estado), uma vez que o sistema econômico liberal precisaria ser autônomo o suficiente para ditar suas regras. Consequentemente, uma economia de mercado somente seria possível em uma sociedade de mercado (POLANYI, 2012, p. 77).

A ideia difundida pelo liberalismo de ausência estatal da economia era um slogan vazio, pois a autorregulação foi fruto de forte intervenção, de modo que Estado e Mercado mantêm uma relação de interdependência. "O 
caminho para o mercado livre estava aberto e assim se mantinha através do incremento de um intervencionismo contínuo, controlado e organizado de forma centralizada" (POLANYI, 2012, P. 157).

Ora, a política econômica do planejamento é compatível com a liberdade, sem um viés individualista, visando à integração do homem no meio social, de modo que haja liberdade e igualdade na comunhão de interesses. Mais do que isso, o planejamento é responsável por suprir e por complementar a liberdade real em prol do desenvolvimento nacional (ADRI, 2010, p. 128).

Ademais, o ideal de liberdade difundido mascarava as distorções sociais ainda hoje presentes, especialmente no Brasil, dentre as quais se cita a desigualdade em suas várias espécies (econômica, social, política). Deste modo, o ideal democrático de participação popular e de detenção do poder político é, na realidade, falacioso quando não é viabilizada a efetiva participação igualitária dos indivíduos no novo sistema em que estão inseridos.

Para Comparato (1989, p. 15), os direitos garantidos nas Constituições, para serem gozados pelos indivíduos a quem se destinam, pressupõem a garantia de um conjunto de pré-condições econômicas e sociais, como instrução, rendimentos, saúde e alimentação.

Nesse sentido, Oliveira (2015, p. 376) afirma que, por ser a democracia um regime de confiança, será mais sólida na medida em que as oportunidades de participação forem formais e materialmente iguais e, do mesmo modo, quanto menor for o nível de participação, menor será o nível democrático da sociedade.

À luz da Constituição econômica de 1988 e das políticas pertinentes ao Estado, a concepção de democracia reduzida, passivamente, à mera liberdade formal mostra-se insuficiente, uma vez que ao indivíduo deve ser dada a oportunidade de participação nas decisões a respeito da política econômica.

O contraste com o período de ditadura militar vivenciado pelo Brasil (1964 - 1985) é um exemplo da necessidade de controle da política econômica por parte dos cidadãos. Conforme registrado por Tavares (2015, p. 1061), a política econômica excludente praticada à época encontrou espaço no regime político que se vivia, uma vez que o governo se valia de 
um poder centralizado, de repressão às liberdades de expressão e de manifestação, além de restrições de igualdade nas disputas eleitorais.

Desta forma, as políticas engendradas nesse período repressivo abrangiam interesses de uma pequena parcela que não correspondia ao interesse nacional. Não por acaso a Constituição de 1988, de base democrática, elenca como fundamento da República Federativa do Brasil ${ }^{8} \mathrm{o}$ princípio da soberania, que também é princípio regente da Ordem Econômica e Financeira ${ }^{9}$.

O controle democrático das políticas econômicas é essencial na condução das medidas adotadas pelo governo, de sorte que a sociedade faça uso dos mecanismos democráticos como maneira de impedir que a gestão econômica do país seja direcionada novamente de acordo com o interesse de uma pequena parcela da sociedade ou da economia (TAVARES, 2015, p. 1064).

A participação popular nas políticas econômicas possibilita a democratização, inclusive quanto à distribuição dos recursos disponíveis para suprir as necessidades de toda a sociedade, de modo a evitar a sua concentração em reduzida parcela social. De acordo com Oliveira (2015, p. 385), isso é um pressuposto importante para garantir o desenvolvimento em sociedades que ainda não o alcançaram.

Nesse sentido, Comparato (1989, p. 132) entende que os planos de desenvolvimento devem conter a participação obrigatória de representantes da comunidade, de maneira que a política desenvolvimentista deixe de ser tarefa estritamente burocrática para ser função de interesse coletivo.

Isto porque o desenvolvimento e a democracia são elementos da Constituição que devem fomentar a política econômica e, de modo especial, o planejamento. Conforme exposto anteriormente, a intervenção do Estado visa atingir os objetivos dispostos na Constituição, dentre os quais se destaca o desenvolvimento. Como técnica interventiva, o planejamento destina-se,

\footnotetext{
${ }^{8}$ Art. $1^{\circ}$ A República Federativa do Brasil, formada pela união indissolúvel dos Estados e Municípios e do Distrito Federal, constitui-se em Estado Democrático de Direito e tem como fundamentos: I - a soberania; [...] (BRASIL, 1998).

9 Art. 170. A ordem econômica, fundada na valorização do trabalho humano e na livre iniciativa, tem por fim assegurar a todos existência digna, conforme os ditames da justiça social, observados os seguintes princípios: I - soberania nacional; [...] (BRASIL, 1988).
} 
igualmente, à aplicabilidade das diretrizes propostas pela ideologia constitucionalmente adotada.

Para Bercovici (2006, p. 251), a rediscussão a respeito de um projeto nacional de desenvolvimento demanda a reestruturação do Estado, que encontra seus fundamentos na Constituição de 1988, a qual possibilita a transformação das estruturas sociais.

Por assim ser, é possível dizer que a Constituição de 1988 possibilita a construção de uma sociedade de bem-estar, pois o direito econômico oferece os instrumentos para a organização do processo econômico capitalista, tal qual o planejamento, que pode ser usado pelo Estado como instrumento transformador da economia, vinculado a objetivos sociais e coletivos (BERCOVICI, 2009, p.518).

Diante do exposto, o controle social, necessário à democracia, é medida que vai ao encontro da política econômica do planejamento, a qual somente será legítima se estiver de acordo com a ideologia disposta na Constituição, uma vez que é objetivo de toda a atuação do poder econômico público "indicar o sentido da 'economicidade' pelo qual a ideologia se satisfaça e justifique as medidas de Política Econômica a serem praticadas" (SOUZA, 1994, p. 258).

Em termos de política econômica, que é objeto de regulamentação pelo Direito Econômico, é obrigatório que se obedeça aos elementos do ordenamento jurídico capazes de consolidar os princípios presentes na legislação ordinária que coincida com o estado atual para modificá-lo, a fim de atingir os objetivos fundamentais da República (art. $3^{\circ}, \mathrm{CF} / 88$ ). Em busca dessa finalidade, o princípio da coerência aplica-se ao Direito Econômico pela compatibilidade entre os objetivos constitucionais e as medidas aptas a concretizá-los (SOUZA, 1994, p. 339).

Portanto, por meio da Constituição de 1988 houve a compatibilização entre o planejamento e a democracia, de modo que o Estado Democrático de Direito possui base legal expressa de intervenção na ordem econômica, de maneira que a democracia caminha ao lado da organização planejada pelo Estado, a qual visa aos objetivos constitucionais para seus indivíduos.

Em que pese o arcabouço constitucional acima mencionado, na atualidade, o Brasil abandonou o planejamento econômico macro, não sendo possível dizer se o país pretende regredir e se focar no agronegócio para 
exportação, sem agregar qualquer valor às commodities comercializadas, como diversas atitudes governamentais fazem crer, ou se deve buscar sua reindustrialização e o avanço para a Revolução 4.0.

O Estado brasileiro segue tal qual uma "nave" sem rumo, na medida em que se olvidou do papel de planejar o desenvolvimento do país, em violação a diversos preceitos da Constituição de 1988, o que precisa mudar, sob pena de manter-se a pobreza, o desemprego e a desigualdade social que o vem caracterizando.

\section{CONSIDERAÇÕES FINAIS}

A partir de 1930, observou-se o desempenho de funções cada vez mais complexas pelo Estado na economia, de tal sorte que se chegou à política econômica planificada (IANNI, 2009, p. 281). Após crises econômicas e políticas pelas quais o Brasil passou, a exemplo da crise do sistema cafeeiro (1929-1933) e da II Guerra Mundial (1939 - 1945), o poder público passou a intervir na vida econômica do País, protegendo e incentivando algumas atividades produtivas.

A história do Brasil comprova que grandes mudanças econômicas foram consequências de ações planejadas do Estado, o qual foi impelido a atuar em momentos de crise. Exemplificativamente, a política industrial, iniciada no governo de Getúlio Vargas e continuada no governo de Juscelino Kubitscheck, aponta que, ao contrário do que a lógica do livre mercado possa levar a crer ao naturalizar a atividade mercadológica, os rumos macroeconômicos partem de uma escolha política (TAVARES, 2015, p. 1064).

O planejamento, enquanto política econômica de intervenção do Estado no domínio econômico, é, portanto, fruto de uma escolha do Estado em dois sentidos: primeiramente, a opção pelo seguimento da intervenção e, em segundo lugar, pela forma como essa intervenção irá ocorrer (SOUZA, 2002 b, p. 197- 203).

A Constituição Federal de 1988 estabelece as bases para a aplicação do instituto do planejamento econômico, considerando-o como determinante ao setor público e indicativo ao setor privado. Com isso, há uma reunião dos 
interesses público e privado para a consecução dos objetivos dispostos na Constituição, de acordo com a ideologia constitucionalmente adotada.

A direção da política econômica do planejamento em bases democráticas é essencial ao alcance do desenvolvimento nacional enquanto objetivo da República Federativa do Brasil, uma vez que o sistema democrático possibilita a realização de controles por parte do povo, de modo que a redistribuição racional dos recursos e a garantia do bem-estar sejam possíveis, ao contrário de modelos autoritários de crescimento econômico já muito vivenciados pelo nosso País.

Por assim ser, é preciso que o instituto do planejamento seja pensado por um viés democrático, de modo que a política econômica beneficie a coletividade e seja construída com base no interesse nacional.

\section{REFERÊNCIAS}

ADRI, Renata Porto. O planejamento da atividade econômica como dever do Estado. Belo Horizonte: Fórum, 2010.

BERCOVICI, Gilberto. Constituição Econômica e Desenvolvimento: uma leitura a partir da Constituição de 1988. São Paulo: Malheiros, 2005.

BERCOVICI, Gilberto. Constituição Econômica e Constituição

Dirigente. In: BONAVIDES, Paulo; LIMA, Francisco Gérson Marques de \& BEDÊ, Fayga Silveira (coords.), Constituição e Democracia: Estudos em Homenagem ao Professor J. J. Gomes Canotilho, São Paulo, Malheiros, 2006.

BERCOVICI, Gilberto. O Ainda Indispensável Direito Econômico. In: BENEVIDES, Maria Victoria de Mesquita; BERCOVICI, Gilberto \& MELO, Claudineu de (orgs.), Direitos Humanos, Democracia e República: Homenagem a Fábio Konder Comparato, São Paulo: Quartier Latin, 2009.

BERCOVICI, Gilberto. O planejamento e a Constituição de 1988. In: SCAFF, Fernando Facury. Constitucionalizando direitos aos 15 anos da Constituição Brasileira de 1988. Rio de Janeiro: Renovar, 2003. 
COMPARATO, Fábio Konder. O Indispensável Direito Econômico. Revista dos Tribunais nº 353, São Paulo, março de 1965.

COMPARATO, Fábio Konder. Para viver a democracia. São Paulo: Brasiliense, 1989.

FURTADO, Celso. Formação econômica do Brasil. 34 ed. São Paulo: Companhia das Letras, 2007.

GRAU, Eros Roberto. A ordem econômica na Constituição de 1988. 15 ed. São Paulo: Malheiros, 2012.

FILHO, T.H. et al. Direito Econômico : estudos em homenagem ao professor Giovani Clark. Belo Horizonte: D’Plácido, 2015.

IANNI, Octávio. A era do globalismo. 12. ed. Rio de Janeiro: Civilização Brasileira, 2014.

IANNI, Octávio. Estado e planejamento econômico no Brasil. Rio de Janeiro, Editora UFRJ, 2009.

POLANYI, Karl. A Grande Transformação: As Origens da Nossa Época. 2 ed. Rio de Janeiro: Campus, 2012.

PRADO Jr., Caio. História Econômica do Brasil. 43 ed. São Paulo: Brasiliense, 2012.

SOUZA, Washington Peluso Albino de. Direito Econômico. São Paulo, Saraiva, 1980.

SOUZA, Washington Peluso Albino de. Lições de Direito Econômico. Porto Alegre: Sergio Antonio Fabris, 2002a.

SOUZA, Washington Peluso Albino de. Primeiras Linhas de Direito Econômico. 3 ed, São Paulo: LTr, 1994.

SOUZA, Washington Peluso Albino de. Teoria da constituição econômica. Belo Horizonte: Del Rey, 2002b.

TAVARES, André Ramos. Direito constitucional econômico. 3. ed. São Paulo: Método, 2011.

TAVARES, André Ramos. Facções privadas e política econômica nãodemocrática da ditadura brasileira. Revista Brasileira de Estudos Constitucionais - RBEC, Belo Horizonte, ano 9, $\mathrm{n}^{\circ}$ 32, maio/agosto 2015. 
(c) Este trabalho possui uma Licença Creative Commons -

Como citar este artigo (ABNT)

KOURY, Suzy Elizabeth Cavalcante; LIMA, Amanda Naif Daibes. A Essencialidade do Planejamento Econômico para o Alcance do Desenvolvimento Nacional. Revista Semestral de Direito Econômico, Porto Alegre, v. 01, n. 02, e01203, jul./dez. 2021. https://doi.org/10.51696/resede.e01203

Recebimento: 01/02/2021

Avaliação preliminar: 01/02/2021

Aprovação: 26/01/2022

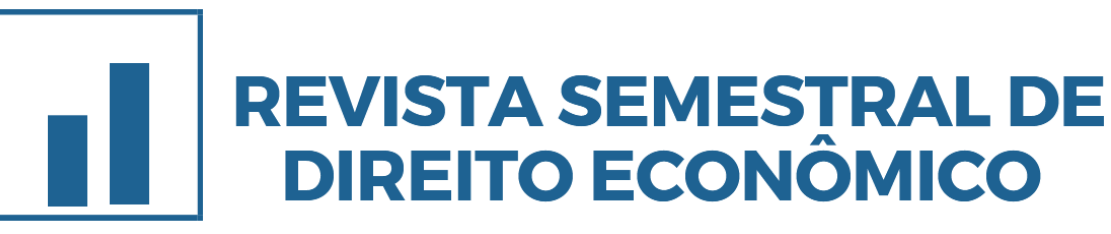

